\title{
The impact of diurnal variability in sea surface temperature on the central Atlantic air-sea $\mathrm{CO}_{2}$ flux
}

\author{
H. Kettle ${ }^{1}$, C. J. Merchant ${ }^{1}$, C. D. Jeffery ${ }^{2}$, M. J. Filipiak ${ }^{1}$, and C. L. Gentemann ${ }^{3}$ \\ ${ }^{1}$ School of GeoSciences, The University of Edinburgh, UK \\ ${ }^{2}$ National Oceanography Centre, Southampton, UK \\ ${ }^{3}$ Remote Sensing Systems, Santa Rosa, CA, USA \\ Received: 18 July 2008 - Published in Atmos. Chem. Phys. Discuss.: 19 August 2008 \\ Revised: 10 December 2008 - Accepted: 17 December 2008 - Published: 26 January 2009
}

\begin{abstract}
The effect of diurnal variations in sea surface temperature (SST) on the air-sea flux of $\mathrm{CO}_{2}$ over the central Atlantic ocean and Mediterranean Sea $(60 \mathrm{~S}-60 \mathrm{~N}, 60 \mathrm{~W}-45 \mathrm{E})$ is evaluated for 2005-2006. We use high spatial resolution hourly satellite ocean skin temperature data to determine the diurnal warming $(\triangle \mathrm{SST})$. The $\mathrm{CO}_{2}$ flux is then computed using three different temperature fields $-\mathrm{a}$ foundation temperature $\left(T_{f}\right.$, measured at a depth where there is no diurnal variation), $T_{f}$ plus the hourly $\Delta \mathrm{SST}$ and $T_{f}$ plus the monthly average of the $\Delta$ SSTs. This is done in conjunction with a physically-based parameterisation for the gas transfer velocity (NOAA-COARE). The differences between the fluxes evaluated for these three different temperature fields quantify the effects of both diurnal warming and diurnal covariations. We find that including diurnal warming increases the $\mathrm{CO}_{2}$ flux out of this region of the Atlantic for 20052006 from $9.6 \mathrm{Tg} \mathrm{Ca}^{-1}$ to $30.4 \mathrm{Tg} \mathrm{Ca}^{-1}$ (hourly $\Delta \mathrm{SST}$ ) and $31.2 \mathrm{Tg} \mathrm{Ca}^{-1}$ (monthly average of $\Delta \mathrm{SST}$ measurements). Diurnal warming in this region, therefore, has a large impact on the annual net $\mathrm{CO}_{2}$ flux but diurnal covariations are negligible. However, in this region of the Atlantic the uptake and outgassing of $\mathrm{CO}_{2}$ is approximately balanced over the annual cycle, so although we find diurnal warming has a very large effect here, the Atlantic as a whole is a very strong carbon sink (e.g. $-920 \mathrm{Tg} \mathrm{C} \mathrm{a}^{-1}$ Takahashi et al., 2002) making this is a small contribution to the Atlantic carbon budget.
\end{abstract}

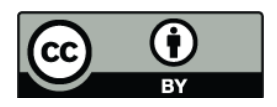

Correspondence to: $\mathrm{H}$. Kettle (h.kettle@ed.ac.uk)

\section{Introduction}

During the day, the upper $2 \mathrm{~m}$ of the ocean typically absorbs about $50 \%$ of the solar radiation reaching its surface. At night this layer then cools, losing heat to the atmosphere through radiative latent and sensible heat fluxes. This diurnal heating and cooling can lead to significant variations in the sea surface temperature (SST) (e.g., Stuart-Menteth et al., 2003; Gentemann et al., 2003). Here we investigate the impact of diurnal variability in SST on $\mathrm{CO}_{2}$ fluxes by using SST data from the Spinning Enhanced Visible and Infrared Imager (SEVIRI) geostationary satellite. Typical regional and seasonal variations in diurnal warming over the SEVIRI disk region are shown in Fig. 1. Due to averaging, diurnal changes in SST ( $\triangle$ SST) shown in Fig. 1 are only up to $1.5 \mathrm{~K}$ but on individual days localised warming can be as much as $6 \mathrm{~K}$ within a shallow warm layer at the sea surface (Merchant et al., 2008; Stramma et al., 1986).

The sea-air flux of $\mathrm{CO}_{2}, F$, is controlled by the transfer of $\mathrm{CO}_{2}$ across the aqueous boundary layer (a layer $\sim 250 \mu \mathrm{m}$ thick just below the air-sea interface, Doney, 1995), such that

$F=k\left(\left[\mathrm{CO}_{2 b}\right]-\left[\mathrm{CO}_{2 s}\right]\right)$

(Liss and Slater, 1974) where $k$ is the gas transfer velocity, $\left[\mathrm{CO}_{2}\right]$ is the $\mathrm{CO}_{2}$ concentration at the base of the mass boundary layer (subscript $b$ ) and at the sea surface skin (subscript $s$ ). However, in practice, seawater $\mathrm{CO}_{2}$ concentration is not measured at the base of the mass boundary layer but normally a few metres below the sea surface - we denote this $\left[\mathrm{CO}_{2 w}\right]$ and the corresponding water temperature, $T_{w}$. The change in $\mathrm{CO}_{2}$ concentration with temperature is

Published by Copernicus Publications on behalf of the European Geosciences Union. 


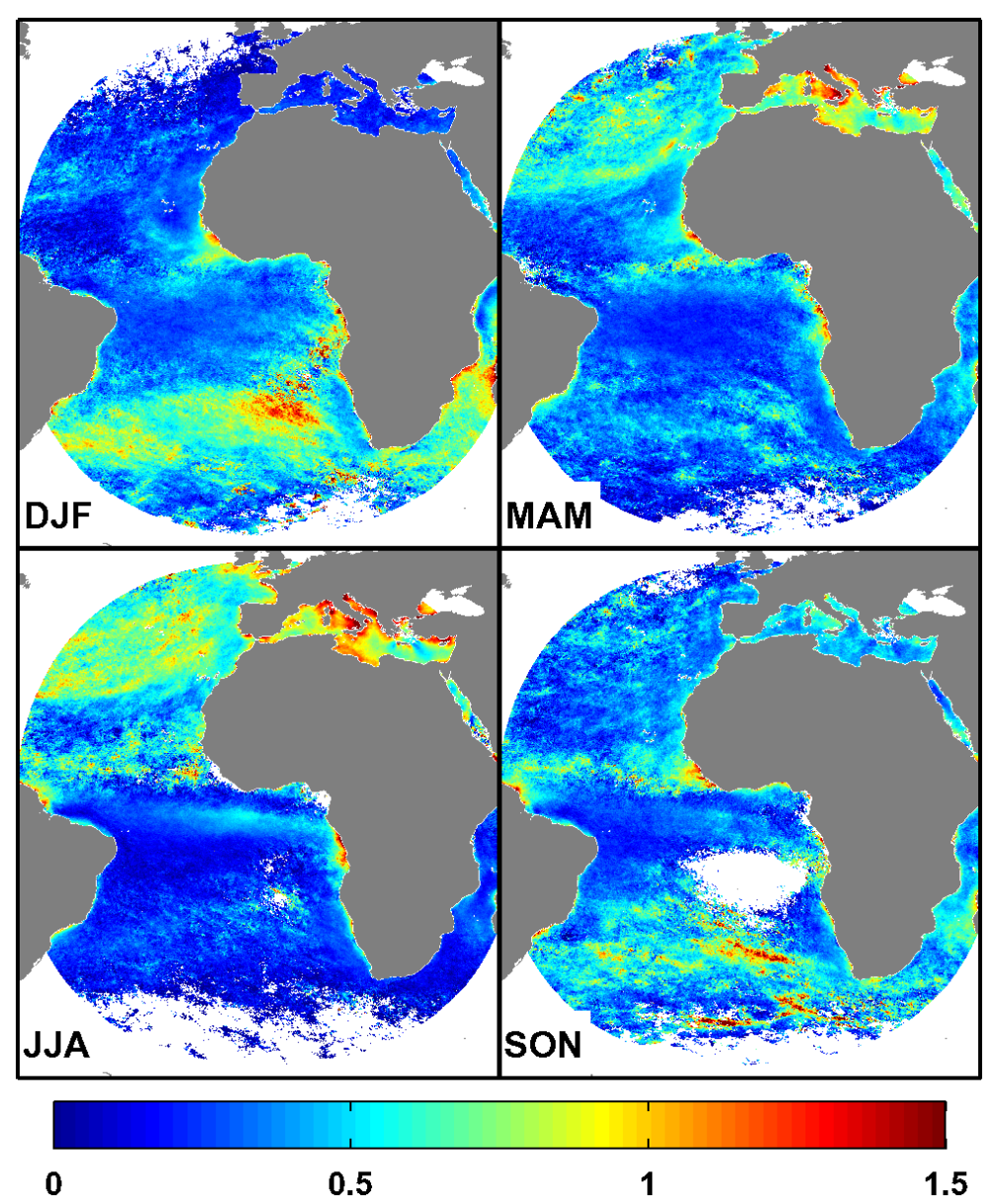

Fig. 1. Seasonal means of the mean daily peak $\Delta$ SST (K) calculated from SEVIRI observations from June 2004 to May 2007 , for northern winter (DJF), spring (MAM), summer (JJA) and autumn (SON). Regions with no valid data are marked white.

$\sim 1.5 \%{ }^{\circ} \mathrm{C}^{-1}$ (Hare et al., 2004; McGillis and Wanninkhof, 2006) therefore Eq. (1) can also be expressed:

$$
F=k\left(\left[\mathrm{CO}_{2 w}\right]\left(1+0.015\left(T_{b}-T_{w}\right)\right)-\left[\mathrm{CO}_{2 s}\right]\right)
$$

where $T_{b}$ is the temperature at the base of the mass boundary layer. The concentration of $\mathrm{CO}_{2}$ can be expressed as a combination of the solubility of $\mathrm{CO}_{2}$ in sea water $(\alpha)$ and its fugacity - or more commonly its partial pressure (we assume these are equivalent since the error is less than $0.5 \%$ over the relevant temperature range, McGillis and Wanninkhof, 2006), so that:

$F=k\left(\alpha_{w} p \mathrm{CO}_{2 w}\left(1+0.015\left(T_{b}-T_{w}\right)\right)-\alpha_{s} p \mathrm{CO}_{2 a}\right)$

where $p \mathrm{CO}_{2}$ is the partial pressure of $\mathrm{CO}_{2}$ in air. The term $0.015\left(T_{b}-T_{w}\right)$ represents $1.5 \%$ of the diurnal warming - this is such a small amount we consider it to be negligible so that the final equation for $\mathrm{CO}_{2}$ flux now becomes

$F=k\left(\alpha_{w} p \mathrm{CO}_{2 w}-\alpha_{s} p \mathrm{CO}_{2 a}\right)$.

Because dissolved $\mathrm{CO}_{2}$ in the ocean is strongly buffered by dissolved inorganic carbon species, the transfer of $\mathrm{CO}_{2}$ across the interface does not significantly affect the total dissolved $\mathrm{CO}_{2}$ concentration (i.e., we assume $p \mathrm{CO}_{2 w}$ is not affected by the flux). Diurnal variability in SST will cause variations in the variables measured at the ocean surface $\left(\alpha_{s}\right.$, $k$ and $p \mathrm{CO}_{2 a}$ ) leading to diurnal variations in $F$. Thus, this study uses high resolution satellite measurements of the ocean skin temperature to estimate $\mathrm{CO}_{2}$ flux.

Previous studies have suggested the "thermal skin effect" (cooling/warming of the upper few millimetres of the ocean) affects flux (e.g. Robertson and Watson, 1992; Van Scoy et al., 1995), as does the warming of the upper few metres of the ocean by solar radiation (McNeil and Merlivat, 1996). Work by Olsen et al. (2004) and McNeil and Merlivat (1996) on this topic differs from the study herein, in that they use a wind-based parameterisation for the gas transfer velocity and averaged values of diurnal warming. These two simplifications may underestimate the importance of diurnal warming. This is because averaging eliminates covariations between variables and wind-based transfer velocities predict no gas flux when there is no wind, which are the conditions under 
which large $\Delta$ SSTs may occur. Moreover, a field experiment has shown that it is possible for $\mathrm{CO}_{2}$ fluxes to have only a weak dependence on wind speed but a strong dependence on the diurnal heating cycle (e.g., GasEx-2001 in the Equatorial Pacific; McGillis et al., 2004). Therefore, in this study we use a more complex physically-based parameterisation that includes buoyancy driven, as well as wind driven, gas transfer, by Fairall et al. (2000) with modifications by Jeffery et al. (2007); along with a slightly different formulation for the flux (Eq. 4).

Since we are investigating gas flux through the air-sea interface, we define the SST to be the temperature of the ocean skin $\left(T_{S}\right)$. We can express this in terms of a foundation (or bulk) temperature (Donlon et al., 2007) below the diurnally warmed layer $\left(T_{f}\right)$, the temperature difference associated with diurnal heating $\left(\Delta T_{d w}\right)$ and the temperature difference across the skin, $\left(\Delta T_{S}\right)$ such that,

$T_{s}=T_{f}+\Delta T_{d w}-\Delta T_{s}$.

The impact of temperature on $\mathrm{CO}_{2}$ flux is investigated by computing fluxes over the SEVIRI disk region using

$F=k^{T}\left(\alpha^{T_{f}} p \mathrm{CO}_{2 w}^{T_{f}}-\alpha^{T} p \mathrm{CO}_{2 a}^{T}\right)$

which is just Eq. (4) with superscripts denoting the temperature at which the variable is computed. $T$ is then defined according to the following three scenarios:

Scenario 1 The specified temperature is equivalent to the foundation temperature. This is the most commonly used temperature and ignores both the skin effect and diurnal variations:

$T(x, y, t)=T_{f}(x, y, t)$.

We use this to calculate $\mathrm{CO}_{2}$ flux over the complete SEVIRI disk with no account taken of diurnal warming - the flux generated is denoted $F_{f}$ and evaluated by substituting for $T$ in Eq. (6).

Scenario 2 This examines the effect of diurnal variability on $\mathrm{CO}_{2}$ flux by using a temperature with hourly estimates of the diurnal variability included (Eq. 5):

$T(x, y, t)=T_{S}(x, y, t)$.

For a given time slot this will only cover a small fraction of the SEVIRI disk because we only use locations where warming occurs (i.e. $\Delta \mathrm{SST}>0$ ) and where there are data available (i.e. pixels not obscured by cloud). $\Delta T_{d w}-\Delta T_{s}$ is estimated from satellite measurements (see Sect. 3.1) and $T_{f}$ is as in Scenario 1. The flux computed under these conditions is denoted $F_{d v}$ and evaluated by substituting for $T$ in Eq. (6).

Scenario 3 This investigates the impact of using the mean diurnal warming measured over a month (computed from the hourly estimates), on $\mathrm{CO}_{2}$ flux. Note that this is not the actual monthly mean diurnal warming since we normally do not have measurements of $\Delta$ SST for every time slot and we only consider $\Delta \mathrm{SST}>0$. The temperature used is the foundation temperature plus the mean warming, (denoted by $\left.\overline{\Delta T_{d w}-\Delta T_{s}}\right)$ :

$T(x, y, t)=T_{f}(x, y, t)+\overline{\Delta T_{d w}(x, y)-\Delta T_{s}}$.

This gives flux estimates accounting for the increase in SST due to diurnal warming but with no diurnal time structure, denoted $F_{w}$ and evaluated by substituting for $T$ in Eq. (6).

The difference between the $\mathrm{CO}_{2}$ flux fields resulting from Scenarios 1 and $2\left(F_{d v}-F_{f}\right)$ examines the effect of the increase in SST caused by diurnal warming. The difference between Scenarios 2 and $3\left(F_{d v}-\mathrm{F}_{w}\right)$ examines the effect of the diurnal covariability of SST with the other factors affecting flux.

\section{Data}

Satellite observations of SST, surface solar irradiance (SSI) and downward longwave irradiance (DLI) are provided by EUMETSAT's Ocean and Sea-Ice Satellite Application Facility (OSISAF), and consist of hourly fields over a field of view that encompasses the east Atlantic Ocean and the Mediterranean Sea (Fig. 1). SSTs are derived from the SEVIRI radiances (OSISAF, Atlantic Sea Surface Temperature Product Manual, Version 1.6, October 2006, http://www. osi-saf.org/biblio/docs/ss1_pmatlsst_1_6.pdf). The resolution of the data is $0.05^{\circ}$ and geographical coverage is $60^{\circ} \mathrm{S}$ to $60^{\circ} \mathrm{N}, 60^{\circ} \mathrm{W}$ to $45^{\circ} \mathrm{E}$ (the disk is approximately a fifth of Earth's total surface area). Data with satellite zenith angle greater than $60^{\circ}$ were excluded due to the potential unreliability of cloud screening and poorer SST precision. The difference between the SEVIRI SSTs and matched drifting buoys (between July 2004 and July 2005) has mean standard deviation of $\sim 0.01 \pm 0.49 \mathrm{~K}$ which includes both drifter errors and spatially correlated retrieval errors. SSTs are only measurable when the sky is clear, so each data point is assigned a confidence level ranging from 1 ("bad") to 5 ("excellent"), depending on the possible cloud contamination (LeBorgne et al., 2006). We bin the data onto a $0.2^{\circ}$ grid to increase the apparent completeness (in space and time) of the SST data and to decreases the SST error in a cell due to retrieval noise. This spatial averaging may dampen the amplitudes of very localised diurnal warming but was necessary due to computing constraints. This SST dataset is used to compute the diurnal warming, $\Delta T_{d w}-\Delta T_{S}$ (see Methods section).

In addition to the SST dataset described above, a foundation SST data set, provided by Meteo-France, is also used. This is an analysis of night-time sub-skin SSTs optimally interpolated to 00:00 UTC daily. It is this dataset that is used to provide the values of $T_{f}$ in the three scenarios (not 

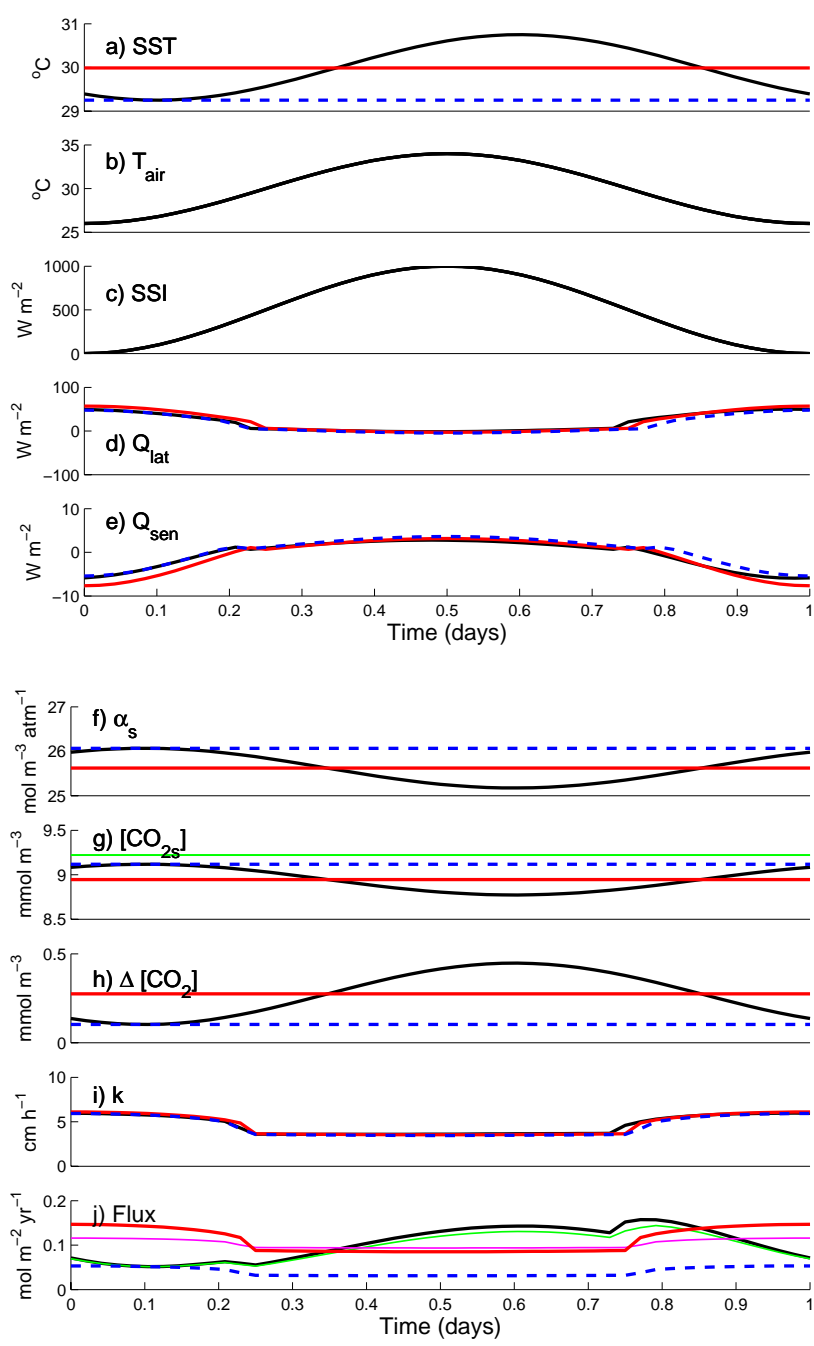

Fig. 2. Times series plots showing modelled response to theoretical forcing from SST (a), air temperature (b) and SSI (c) at steady wind speed of $1 \mathrm{~m} \mathrm{~s}^{-1}$, air pressure of $1000 \mathrm{mb}, \mathrm{MLD}=20 \mathrm{~m}$, salinity $=36$, $\mathrm{DLI}=18.5 \mathrm{~W} \mathrm{~m}^{-2}, \mathrm{CO}_{2}$ concentration in dry air of $364 \mathrm{ppm}$, and dew point temperature at $4{ }^{\circ} \mathrm{C}$ below air temperature. Where there are three lines in a plot, the colours correspond to the SST time series shown in (a) i.e. black is for a diurnally varying SST; red is the daily mean SST; and blue (dashed) is the foundation temperature. In plot (g) the thin green line denotes $\left[\mathrm{CO}_{2 w}\right]$; in plot (h) $\Delta\left[\mathrm{CO}_{2}\right]$ denotes the term in brackets in Eqs. (1 and 2); in plot (j) the thin green line shows flux computed using Eq. (32) and the thin magenta line shows flux computed using Eq. (33).

the SEVIRI SSTs). The wind speeds used in this analysis are the NASA Atlas First-LooK (FLK) version 1.1 derived surface winds level 3.0 product which uses available passive microwave satellite wind speeds produced by Remote Sensing Systems and described at http://sivo.gsfc.nasa.gov/ oceanwinds/. All satellite measurements are processed in a consistent manner using a physically-based retrieval algorithm to determine the wind speed (Wentz, 1997). These wind speeds are used to derive a global 10-m wind speed every $6 \mathrm{~h}$ on a $25 \mathrm{~km}$ grid using variational analysis method (VAM). These data were linearly interpolated in time and space onto the hourly SEVIRI $0.05^{\circ}$ grid. Finally the wind speed data coincident with the grid points of the $0.2^{\circ}$ grid used in this study are extracted.

Other meteorolgical data, pressure $(P)$, dew point temperature $\left(T_{\text {dew }}\right)$ and air temperature $\left(T_{\text {air }}\right)$, are taken from the ECMWF operational dataset (N80 Gaussian gridded analysis on surface levels; in ERA-40 format) at 6-hourly intervals and we linearly interpolate these in time and space. $p \mathrm{CO}_{2 w}$ and salinity $(S)$ are taken from Takahashi's climatology (Takahashi et al., 2002) - hereafter refered to as Taka02 - which is monthly and on $4^{\circ}$ lon $\times 5^{\circ}$ lat grid. Where the Taka02 data are not fully resolved we interpolate longitudinally. We use a monthly climatological dataset for the mixed layer depth (MLD) obtained from Scripps Institution of Oceanography (available from http://ingrid.ldgo.columbia. $\mathrm{edu} / \mathrm{SOURCES} / . \mathrm{IGOSS} /$. sio) with $5^{\circ}$ lon $\times 2^{\circ}$ lat resolution.

\section{Methods}

\subsection{Deriving the diurnal variations in SST}

The SEVIRI satellite measures $T_{s}$ but the processed dataset is corrected for the cool skin by adding $0.2 \mathrm{~K}$. We reverse this correction to retain the original $T_{S}$ measurement. To calculate the diurnal warming, at each hour where there is a SST measurement with confidence level 5 , we compute the difference between it and the "satellite foundation temperature" $\left(T_{s f}\right)$ which we define to be the satellite measured temperature just before the time of local dawn $\left(t_{d}\right)$. Note this is not the same as the foundation temperature previously mentioned $\left(T_{f}\right)$ which is from a different dataset. $T_{s f}$ throughout the rest of the day is approximated using a linear interpolation between consecutive pre-dawn temperatures, such that

$T_{s f}(t)=T_{s}\left(t_{d}\right)+\frac{\left(T_{s}\left(t_{d}+24\right)-T_{s}\left(t_{d}\right)\right)}{24}\left(t-t_{d}\right)$

The diurnal temperature difference at time $t$ is then given by:

$\Delta T_{d w}(t)-\Delta T_{s}(t)=T_{s}(t)-T_{s f}(t)$

\subsection{Computing the $\mathrm{CO}_{2}$ flux}

The following subsections describe the methods for computing the variables needed to evaluate $\mathrm{CO}_{2}$ flux and their reliance on SST. Figure 2 shows how the different quantities change according to theoretical forcing from SST, air temperature, wind speed and solar radiation.

\subsubsection{Solubility, $\alpha$}

The solubility, $\alpha$ of $\mathrm{CO}_{2}$ in sea water is a physical property that determines how much $\mathrm{CO}_{2}$ will dissolve. $\mathrm{CO}_{2}$ is poorly 
soluble in water and its solubility is highly temperature dependent. Solubility (in $\mathrm{mol} \mathrm{m}^{-3}$ atm) can be calculated according to Weiss (1974) by

$$
\begin{aligned}
& \alpha=1000 \exp \left(a_{1}+a_{2} \frac{100}{T_{k}}+a_{3} \log \left(\frac{T_{k}}{100}\right)\right. \\
& \left.+S\left\{b_{1}+b_{2} \frac{T_{k}}{100}+b_{3}\left(\frac{T_{k}}{100}\right)^{2}\right\}\right)
\end{aligned}
$$

where $T_{k}$ is the water temperature (Kelvin), $S$ is salinity, $a_{1}=-58.0931, a_{2}=90.5069, a_{3}=22.2940, b_{1}=0.027766$, $b_{2}=-0.02588, b_{3}=0.0050578$. As the temperature increases the solubility decreases (Fig. 2a and f). To compute the $\mathrm{CO}_{2}$ flux (Eq. 6) for the different scenarios we evaluate $\alpha$ using three different temperatures.

\subsubsection{Gas transfer velocity, $k$}

The gas transfer velocity describes the rate at which a gas moves between the sea and air. The magnitude of the transfer rate is controlled by the thickness of the boundary layer which is a function of near surface turbulence and diffusion. Thus, the transfer rate is determined by the state of the sea surface: by factors such as wave age, fetch, wind speed, the prevalence of bubbles, boundary layer stability and naturally occurring surfactants (e.g. Woolf, 1997; Monahan and Spillane, 1984; Liss and Merlivat, 1986; Asher and Wanninkhof, 1998). It is highly unlikely, therefore, that only one physical variable can completely determine the spatial scales and environmental conditions necessary to predict $k$. Despite this, many empirical relationships for $k$ in practical use are solely functions of wind speed as this is an influential and easily obtainable parameter. Three commonly used wind-based parameterisations are the piecewise linear relation (Liss and Merlivat, 1986), the quadratic relation (Wanninkhof, 1992; Nightingale et al., 2000), and the cubic relation (Wanninkhof and McGillis, 1999).

Using this type of parameterisation to examine the influence of diurnal warming on gas flux will likely result in an under-estimation of the effect because at low wind speeds (when diurnal warming is at its most significant) these parameterisations predict virtually no gas flux. To overcome this limitation we use the NOAA Coupled Ocean Atmosphere Response Experiment (COARE) gas transfer parameterisation (Fairall et al., 2000) which is physically (rather than empirically) based. We also include a modification to this parameterisation by Jeffery et al. (2007) to include the effects of nighttime convective overturn of the water column. A brief description of this method is given below and the variations in $k$ due to wind and tepmerature are shown in Fig. 3.

Fairall et al. (2000) express the transfer velocity as:

$k=\left(\frac{r_{w}}{u_{* w}}+\frac{r_{a} \alpha_{n}}{u_{* a}}\right)^{-1}$,

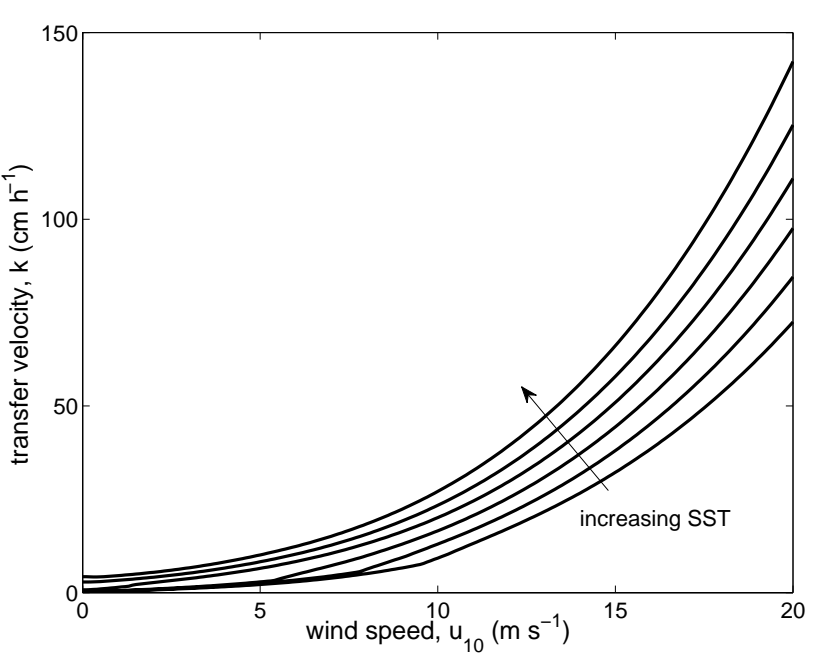

Fig. 3. Transfer velocity as a function of wind speed for SST=5, $10,15,20,25,30^{\circ} \mathrm{C}$, with $P=1000 \mathrm{mb}, \mathrm{SSI}=1000 \mathrm{~W} \mathrm{~m}^{-2}$, DLI $=300 \mathrm{~W} \mathrm{~m}^{-2}, \quad$ salinity $=35, \quad T_{\text {air }}=20^{\circ} \mathrm{C}, \quad \mathrm{MLD}=20 \mathrm{~m}$, $T_{\text {dew }}=15^{\circ} \mathrm{C}$.

where $\alpha_{n}$ is non-dimensionalised solubility $\left(\frac{\alpha R_{\text {gas }}}{T}\right.$; where $R_{\text {gas }}$ is the universal gas constant), $r$ is the "resistance" and $u_{*}$ is the friction velocity (subscripts $a$ and $w$ refer to the air and water sides, respectively). The resistances are given by:

$r_{w}=h_{w} S_{c w}^{\frac{1}{2}}+\ln \left(\frac{z_{w r}}{\delta}\right) / \kappa$,

$r_{a}=h_{a} S_{c a}^{\frac{1}{2}}+C_{d a}^{\frac{1}{2}}-5+\frac{\ln \left(S_{c a}\right)}{2 \kappa}$,

where $S_{c}$ is Schmidt number, $z_{w r}$ is the measurement depth, $\delta$ is the thickness of the cool skin, $C_{d a}$ is the airside drag coefficient and $\kappa$ is the von Karman constant (0.41). The $h$ factors are concerned with the transport through the cool skin layer and are given by $h_{a}=13.3$ and $h_{w}=\frac{13.3 \lambda}{6 A}$ (Saunders, 1967; Soloviev and Schlüssel, 1994) where $\lambda$ is computed according to Fairall et al. (1996a) and $A$ is a tunable constant $(\approx 1)$. If there is no cool skin present $\lambda$ is set to 6 .

Fairall et al. (2000) define the water-side friction velocity $u_{* w}$ by

$u_{* w}=u_{* a}\left(\frac{\rho_{w}}{\rho_{a}}\right)^{-\frac{1}{2}}$.

However, in order to include the increased gas transfer caused by convective overturn, Jeffery et al. (2007) modified the expression for $u_{* w}$ to include waterside "gustiness". Thus $u_{* w}$ is newly defined as

$u_{* w}=\sqrt{C_{d w} S_{w}^{2}}$ 
where $C_{d w}$ is the waterside drag coefficient and $S_{w}$ is an average value of "wind speed", which following Stull (1994) and Godfrey and Beljaars (1991) for the airside, is expressed as

$S_{w}^{2}=u_{\mathrm{ref}}^{2}+w_{g}^{2}$,

where $u_{\text {ref }}$ is analagous to a wind speed at some reference depth $\left(z_{\text {ref }}\right)$, which we can define as

$u_{\mathrm{ref}}=\frac{u_{* w}}{\kappa} \ln \left(\frac{z_{\mathrm{ref}}}{z_{0}}\right)$.

The convective buoyancy/velocity scale, $w_{g}$ is defined as

$w_{g}=\beta\left(-B_{f} Z_{m}\right)^{\frac{1}{3}}$,

where $\beta$ is the (tunable) "gustiness parameter", $Z_{m}$ is the depth of the convective layer (we use monthly climatological MLD) and $B_{f}$ is the buoyancy flux given as the sum of the buoyancy caused by heating and that caused by freshening through evaporation, such that

$B_{f}=\frac{g}{\rho_{w}}\left(\frac{a_{1} Q_{\mathrm{net}}}{C_{p}}-\frac{b_{e} Q_{\mathrm{lat}}}{L_{v}}\right)$,

where $g$ is the acceleration due to gravity, $a_{1}$ is the thermal expansion coefficient $\left(2.1 \times 10^{-5}(T+3.2)^{0.79} \mathrm{~K}^{-1}\right), b_{e}$ is the saline expansion coefficient $(0.026), C_{p}$ is the thermal heat capacity of water and $\rho_{w}$ is the density of seawater (both functions of temperature), $L_{v}$ is the latent heat of vaporization $\left((2.501-0.00237 T) \times 10^{6} \mathrm{~J} \mathrm{~kg}^{-1}\right), Q_{\text {net }}$ is the net heat flux (positive into the water) and $Q_{\text {lat }}$ is the latent heat of evaporation (positive out of water). When the buoyancy flux is positive $w_{g}$ is set to zero as the fluxes serve to stabilize the exchange by adding buoyancy to the surface.

Bubble mediated gas transfer $\left(k_{b}\right)$ is accounted for by modifiying the gas transfer Eq. (13) as follows:

$k=k_{b}+\left(\frac{r_{w}}{u_{* w}}+\frac{r_{a} \alpha_{n}}{u_{* a}}\right)^{-1}$.

where $k_{b}$ is defined by Woolf's (1997) parameterisation:

$k_{b}=B V_{0} f \alpha_{n}\left[1+\left(e \alpha_{n} S_{c w}^{\frac{1}{2}}\right)^{-\frac{1}{n}}\right]^{-n}$,

where

$f=3.84 \times 10^{-6} u_{10}^{3.41}$,

and $V_{0}=6.8 \times 10^{-3} \mathrm{~m} \mathrm{~s}^{-1}, e=14, n=1.2$ and $B$ is a tunable constant.

To solve Eqs. (13 to 24 ) we first compute the heat fluxes ( $Q_{\text {lat }}$ and $\left.Q_{\text {net }}\right)$, the cool skin parameters $(\delta$ and $\lambda$ ) and the drag coefficients $\left(C_{d}\right)$ using code from the air-sea matlab toolbox from Woods Hole Science Center (http://woodshole. er.usgs.gov/operations/sea-mat/index.html; Fairall et al., 1996a, 2000). This requires relative humidity (function of $T_{\text {air }}$ and $T_{\mathrm{dew}}$ ), pressure, air temperature (all from ECMWF), wind speed (satellite data), net short wave radiation (SEVIRI SSI) and net long wave radiation (SEVIRI DLI minus the long wave radiation emitted from the ocean). Figure $2 d-$ e shows an example of computed latent and sensible heat fluxes for time-varying forcing.

The (dimensionless) Schmidt number (used in Eqs. 14 and 15 ) is the kinematic viscosity of the fluid divided by the molecular diffusion coefficient of the gas. For $\mathrm{CO}_{2}$ in seawater $S_{c w}$ can be estimated from a relationship with temperature (Jahne et al., 1987) such that

$S_{c w}=2073.1-125.62 T+3.6276 T^{2}-0.043219 T^{3}$

where $T$ is in ${ }^{\circ} \mathrm{C}$. The Schmidt number for $\mathrm{CO}_{2}$ in air, $S_{c a}$ is kept constant at 0.8 (Fairall et al., 2000) and is much smaller than its waterside equivalent $(\sim 600)$ so that the transfer resistance for $\mathrm{CO}_{2}$ is much greater in water than in air. The gas transfer parameterisation thus contains three empirical parameters which allow tuning to specific data sets: $A$ (related to the thermal sublayer), $B$ (related to bubble mediated transfer) and $\beta$ (the "gustiness" parameter which is related to convective buoyancy effects). Published values of $A$ and $B$ derived from $\mathrm{CO}_{2}$ air-sea flux field experiments are: $A=0.625, B=2.0$ (GasEx 98 - a warm core eddy; Hare et al., 2004), and $A=1.3, B=0.82$ (GasEx 2001 - in the eastern Pacific south of the upwelling region; derived from results by McGillis et al., 2004). Soloviev and Schüssel (1994) use $A=1.85$ and $B=1$ based on radon experiments. Thus, there is a significant amount of uncertainty in these two parameters. The gustiness parameter, $\beta$, has published values of 1.25 (Fairall et al., 1996b), 1.0 (Miller et al., 1991) and 0.7 (Schumann, 1988) - but note that these are for air. Here we are not tuning the parameterisation to a particular data set so we take the generic values of $\beta=1, A=1$, and $B=1$, since these are roughly the mean of the previously published values and are a neutral choice with no scaling up or down.

The small effect of SST on the gas transfer velocity is shown in Fig. 2i for a steady wind speed of $1 \mathrm{~m} \mathrm{~s}^{-1}$. The temperature used to evaluate $k$ (Eq. 13-25) is changed according to the three scenarios outlined in the Introduction.

\subsubsection{The partial pressures of $\mathrm{CO}_{2}$ in the air and sea, $p \mathrm{CO}_{2}$}

Climatological values are available for the concentration of $\mathrm{CO}_{2}$ in dry air and $p \mathrm{CO}_{2 w}$. However, these must be modified to the physical conditions present in 2005-2006. Variations in $p \mathrm{CO}_{2 a}$ with changes in dry air pressure have been shown to be important for flux calculations by Kettle and Merchant (2005). Thus we compute $p \mathrm{CO}_{2 a}$ from:

$p \mathrm{CO}_{2 a}(t)=X_{\left[\mathrm{CO}_{2}\right]}\left(P(t)-p \mathrm{H}_{2} \mathrm{O}(t)\right)$

where $P$ is 6 hourly air pressure (ECMWF), $X_{\left[\mathrm{CO}_{2}\right]}$ is the zonal mean molar fraction of $\mathrm{CO}_{2}$ in the dry atmosphere for 1995 (Globalview- $\mathrm{CO}_{2}, 2000$; and used in Taka02) and $p \mathrm{H}_{2} \mathrm{O}$ is the saturation vapour pressure, which is a function 


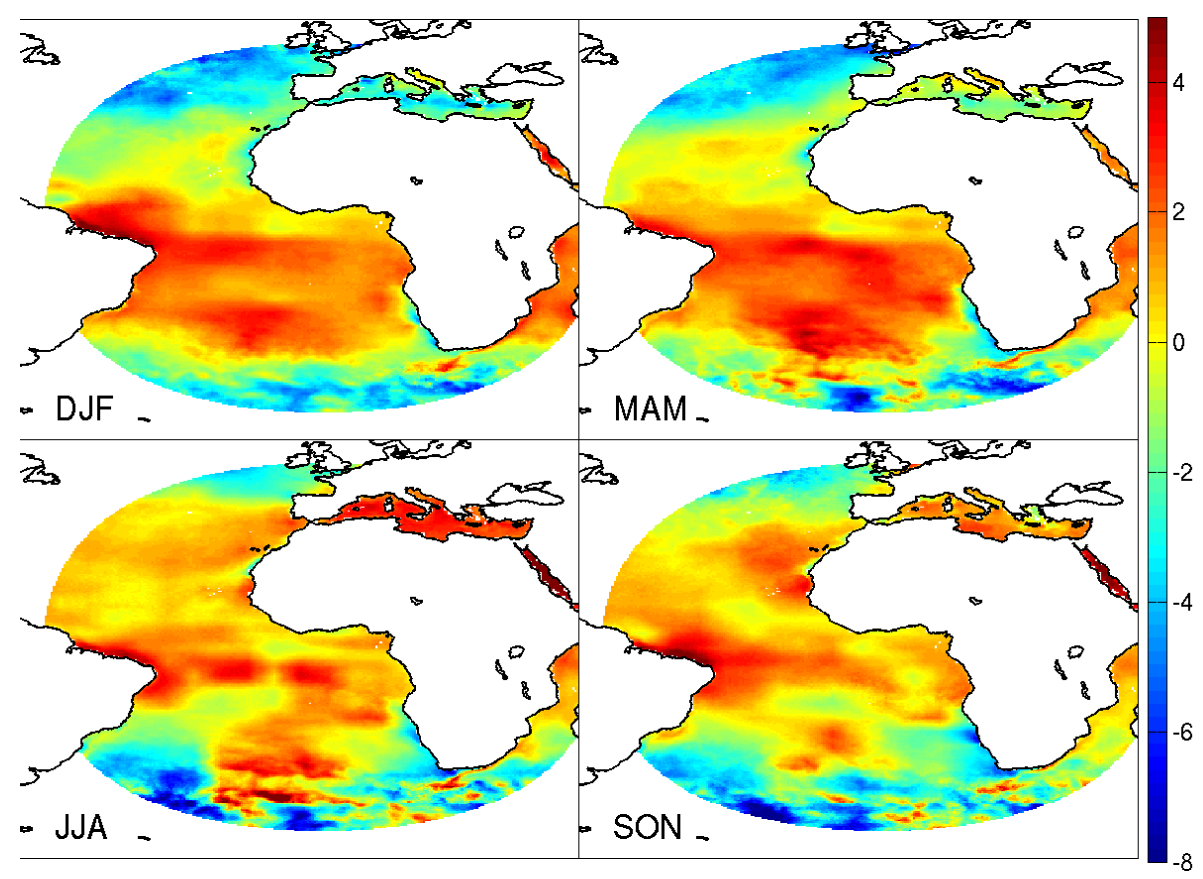

Fig. 4. Average net $\mathrm{CO}_{2}$ flux (mol CO $\mathrm{CO}^{-2} \mathrm{a}^{-1}$ ) for northen winter (DJF), spring (MAM), summer (JJA) and autumn (SON) during 2005-2006 using foundation SST $\left(T_{f}\right)$. Positive flux indicates outgassing of $\mathrm{CO}_{2}$ from the ocean.

of SST and salinity given by Weiss and Price (1980) and then converted to $\mathrm{mb}$ :

$$
\begin{aligned}
& p \mathrm{H}_{2} \mathrm{O}(t)=1013.25 \exp \left(24.4543-67.4509 \frac{100}{T_{k}(t)}\right. \\
& \left.-4.8489 \ln \left(\frac{T_{k}(t)}{100}\right)-0.000544 S\right),
\end{aligned}
$$

where salinity, $S$, is taken from Taka02. When SST rises, $p \mathrm{H}_{2} \mathrm{O}$ increases, causing a small decrease in $p \mathrm{CO}_{2 a}$. The concentration of $\mathrm{CO}_{2}$ at the ocean skin is given by $\alpha_{s} p \mathrm{CO}_{2 a}$ - Fig. $2 \mathrm{~g}$ shows the variation in $\left[\mathrm{CO}_{2 s}\right]$ with SST. Thus $p \mathrm{CO}_{2 s}$ changes according to the three different temperature scenarios.

$p \mathrm{CO}_{2 w}$ does not change between scenarios since it is representative of conditions beneath the surface warm layer. However, the climatological data from Taka02 must be adjusted to the foundation temperature for 2005-2006. The change in $p \mathrm{CO}_{2 w}$ with temperature is given by Takahashi et al. (1993) as

$$
\frac{\partial \ln \left(p \mathrm{CO}_{2 w}\right)}{\partial T}=0.0423 \text {. }
$$

However, it should be noted that $0.0423^{\circ} \mathrm{C}^{-1}$ is an approximation and can range between 0.037 to $0.053{ }^{\circ} \mathrm{C}^{-1}$ depending upon the carbonate dissociation constants used (McGillis and Wanninkhof, 2006). To compute $p \mathrm{CO}_{2 w}(t)$ at our foundation temperature $T_{f}$ we modify the Taka02 values using:

$$
p \mathrm{CO}_{2 w}(t)=p \mathrm{CO}_{2 w}^{\mathrm{Tak}} \exp \left(0.0423\left(T_{f}(t)-T^{\mathrm{Tak}}\right)\right),
$$

where $t$ is time, $p \mathrm{CO}_{2 w}^{\mathrm{Tak}}$ and $T^{\mathrm{Tak}}$ are $p \mathrm{CO}_{2 w}$ and bulk water temperature from Taka02 (monthly climatology). Thus $p \mathrm{CO}_{2 w}$ is always computed using the foundation temperature but $p \mathrm{CO}_{2 a}$ varies between the three scenarios (following the method used by McGillis et al., 2004 and Hare et al., 2004).

\section{Results}

Figure 4 shows seasonal averages of the $\mathrm{CO}_{2}$ flux field for 2005-2006 computed using the analysed foundation SST $\left(T_{f}\right)$. There is strong outgassing of around $2 \mathrm{molCO}_{2} \mathrm{~m}^{-2} \mathrm{a}^{-1}$ from the ocean around the equator, changing to ocean uptake of $\mathrm{CO}_{2}$ beyond the Tropics towards the North and South poles. Regions around $30-40^{\circ} \mathrm{N}$ and $30-40^{\circ} \mathrm{S}$ change seasonally between being sources and sinks of $\mathrm{CO}_{2}$. The plots compare well in terms of magnitude and spatial distribution with the mean annual flux for 1995 shown by Taka02 and serve as a check that the more complex physically-based flux parameterisation, with far more variables, is generally equivalent (at these scales) to other methods.

Using the foundation SST ( $F_{f}$, Scenario 1$)$ gives a mean net mass flux of $9.6 \mathrm{Tg} \mathrm{Ca}^{-1}$ out of the ocean over the SEVIRI disk region for 2005-2006. When satellite-measured diurnal variations are included $\left(F_{d v}\right.$, Scenario 2$)$ this outgassing is increased to $30.4 \mathrm{Tg} \mathrm{Ca}^{-1}$, and when diurnal warming is represented by a monthly-averaged value $\left(F_{w}\right.$, 


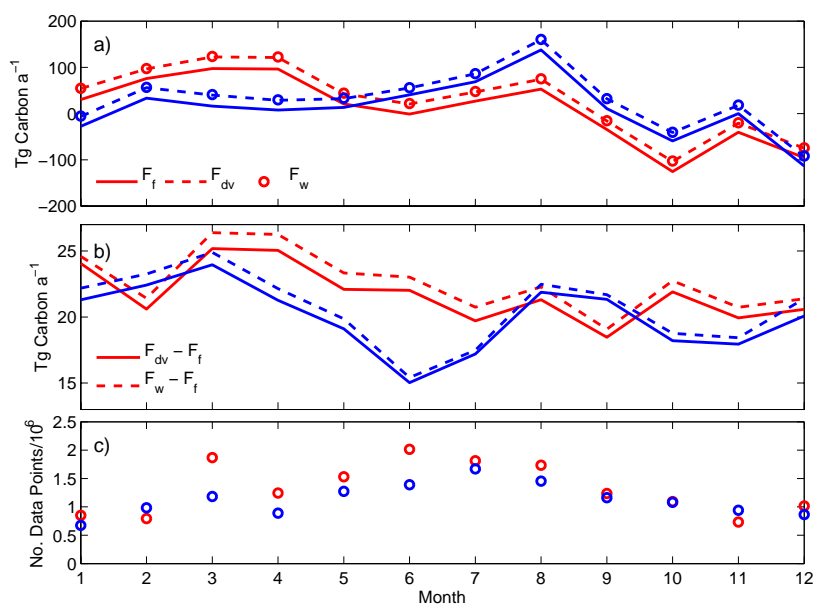

Fig. 5. (a) Monthly-averaged mass flux of carbon over SEVIRI disk computed using the foundation SST ( $F_{f}$; solid line), including diurnal covariations ( $F_{d v}$; dashed line) and including monthly-averaged diurnal warming $\left(F_{w}\right.$; circles); (b) Difference in mass flux caused by including diurnal variations (solid line) and monthly-averaged warming (dashed line); (c) Number of satellite-derived $\Delta$ SST data points available each month. 2005 is shown in red and 2006 in blue.

Scenario 3) the mass flux out of the ocean is $31.2 \mathrm{Tg} \mathrm{Ca}^{-1}$. Figure 5 shows how using the three different SST datasets affects the total mass flux over the SEVIRI disk for each month during 2005 and 2006. Using satellite-measured diurnal warming increases outgassing by $21.7 \mathrm{Tg} \mathrm{C}(2005)$ and 20.0 Tg C (2006) (Fig. 5b). When diurnal covariations are eliminated by using $\triangle$ SST measurements averaged over the month the outgassing is increased (or ingassing is reduced) by a further $0.92 \mathrm{Tg} \mathrm{C}$ (2005) and $0.69 \mathrm{Tg} \mathrm{C} \mathrm{(2006).} \mathrm{Remov-}$ ing diurnal covariations increases the outgassing flux because $\triangle \mathrm{SST}$ and wind speed are negatively correlated leading to less flux when $\triangle \mathrm{SST}$ is high (due to the low wind speed). However, the difference between $F_{d v}$ and $F_{w}$ is small compared with the difference with $F_{f}$ implying that the diurnal covariation effects are much less important than the mean effect of diurnal warming. In Fig. $5 c$ the number of $\Delta S S T$ data points derived from satellite measured SSTs each month is plotted. The number of valid measurements range from a minimum in January 2006 ( 0.67 million) to a maximum in June 2005 (2.01 million).

Since the effect of diurnal covariability is small, in the rest of this section we focus on the differences between using $F_{d v}$ (because it is based on the most detailed data available) and $F_{f}$ (because it is the foundation SST which is most commonly used for estimating $\mathrm{CO}_{2}$ flux). Figure 6 shows the spatial distribution of the mean monthly differences in flux caused by diurnal variability, (i.e., $F_{d v}-F_{f}$ ), averaged over 2005-2006 for each month. Here we see that including diurnal variability in SST either causes an increase in the outgassing of $\mathrm{CO}_{2}$ from the ocean (this may be mani- fested as a reduction in uptake) or no change in flux, everywhere over this region. The maximum increase in monthlyaveraged outgassing is $\sim 0.2 \mathrm{~mol} \mathrm{CO}_{2} \mathrm{~m}^{-2} \mathrm{a}^{-1}$. The seasonal maximum is around $5 \mathrm{molCO}_{2} \mathrm{~m}^{-2} \mathrm{a}^{-1}$ (Fig. 4), however, large regions have zero net flux so the impact of diurnal variability in SST on flux, is regionally very significant. As expected, the impact changes spatially with time of year, with large increases in the Mediterranean in the northern summer $\left(\sim 0.1 \mathrm{~mol} \mathrm{CO}_{2} \mathrm{~m}^{-2} \mathrm{a}^{-1}\right)$ and around South America from June to January, coinciding with areas of large diurnal warming events (Fig. 1). The spatial distribution of the available data points is shown in Fig. 7. The figure shows there are some areas where data is very sparse - this is discussed further in the following section.

\section{Discussion}

The results show that including the increase in SST due to diurnal warming acts to increase the outgassing/reduce the ingassing flux of $\mathrm{CO}_{2}$ from the ocean over the SEVIRI disk region (all other factors being equal). The main factor in the flux equation (Eq. 4) through which $\Delta \mathrm{SST}$ affects flux can be ascertained by differentiating with respect to diurnally varying temperature $\left(T_{d v}\right)$ :

$$
\begin{aligned}
& \frac{\partial F}{\partial T_{d v}}=\left(k \alpha_{w} \frac{\partial p \mathrm{CO}_{2 w}}{\partial T_{d v}}+\alpha_{w} p \mathrm{CO}_{2 w} \frac{\partial k}{\partial T_{d v}}+k p \mathrm{CO}_{2 w} \frac{\partial \alpha_{w}}{\partial T_{d v}}\right) \\
& -\left(k \alpha_{s} \frac{\partial p \mathrm{CO}_{2 a}}{\partial T_{d v}}+\alpha_{s} p \mathrm{CO}_{2 a} \frac{\partial k}{\partial T_{d v}}+p \mathrm{CO}_{2 a} k \frac{\partial \alpha_{s}}{\partial T_{d v}}\right) .
\end{aligned}
$$

Numbering the terms on the right hand side of Eq. (31) from 1-6; we can ignore terms 1 and 3 since these are evaluated at the foundation temperature and will not be affected by diurnal warming. Term 4 can be assumed negligible since $p \mathrm{CO}_{2 a}$ does not vary significantly with temperature so that Eq. (31) becomes:

$$
\frac{\partial F}{\partial T_{d v}} \approx\left(\left[\mathrm{CO}_{2 w}\right]-\left[\mathrm{CO}_{2 s}\right]\right) \frac{\partial k}{\partial T_{d v}}-p \mathrm{CO}_{2 a} k \frac{\partial \alpha_{s}}{\partial T_{d v}} .
$$

In regions where the concentrations of $\mathrm{CO}_{2}$ in the ocean and atmosphere are approximately in balance, such as over the SEVIRI disk, the first term on the right hand side of Eq. (31) is close to zero, implying that the diurnal change in flux is dominated by the change in solubility caused by diurnal variations in the ocean skin temperature. Solubility decreases with temperature so this term is negative, indicating that the flux in the outgassing direction will be increased by diurnal warming. In other words, the change in flux due to diurnal warming $\left(\Delta F_{d v}\right)$, for this region, can be estimated very approximately by:

$\Delta F_{d v} \approx-p \mathrm{CO}_{2 a} k \Delta \alpha_{s}$.

where $\Delta \alpha_{s}$ is the change in surface solubility due to diurnally varying SST. Figure $2 \mathrm{j}$ gives an example of flux computed using this approximation (i.e. $F_{f}+\Delta F_{d v}$ ). 


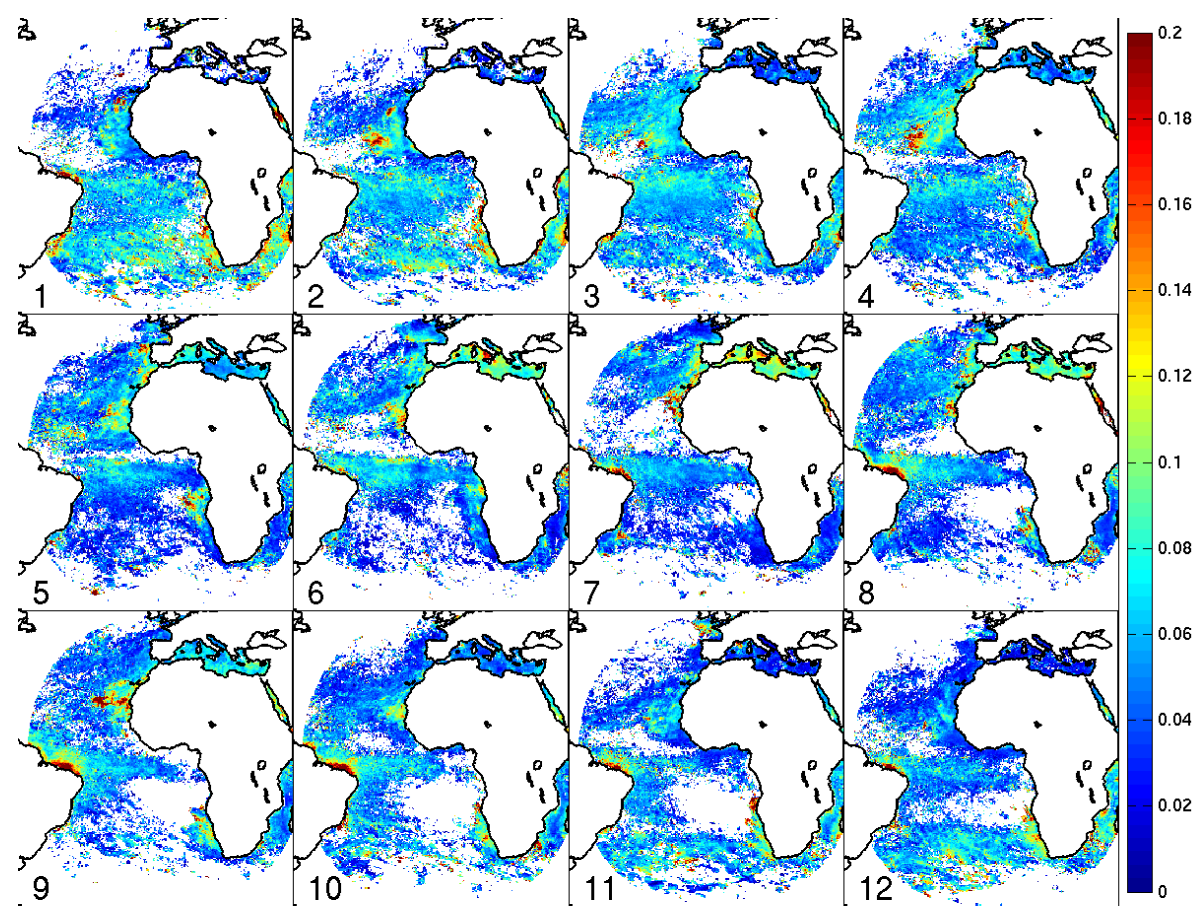

Fig. 6. Average difference in the net $\mathrm{CO}_{2}$ flux $\left(\mathrm{mol} \mathrm{CO}_{2} \mathrm{~m}^{-2} \mathrm{yr}^{-1}\right)$ averaged over each month (numbered) over $2005-2006$ caused by diurnal variations in SST $\left(F_{d v}-F_{f}\right)$. Positive values indicate an increase in outgassing of $\mathrm{CO}_{2}$ from the ocean. White regions indicate missing data.

Using Eq. (32), the average change in flux due to diurnal variations in SST is given by:

$\overline{\Delta F_{d v}} \approx-\left(\overline{p \mathrm{CO}_{2 a}} \overline{k \Delta \alpha_{s}}+\overline{p \mathrm{CO}_{2 a} k^{\prime} \Delta \alpha_{s}^{\prime}}+\bar{k} \overline{p \mathrm{CO}_{2 a}^{\prime} \Delta \alpha_{s}^{\prime}}\right.$

$\left.+\overline{\Delta \alpha_{s}} \overline{p \mathrm{CO}_{2 a}^{\prime} k^{\prime}}+\overline{k^{\prime} p \mathrm{CO}_{2 a}^{\prime} \Delta \alpha_{s}^{\prime}}\right)$

where the overbar denotes the daily average and the prime indicates temporal deviation from this value. Numbering the terms on the right hand side from 1-5, and using the conditions specified in Fig. 2, the sizes of terms 1-3 (in $\mathrm{mol} \mathrm{m}^{-2} \mathrm{a}^{-1}$ ) are $0.0626,-0.0072,-0.0001$ and terms 4, 5 are approximately zero. Thus removing terms $2-5$ only has a small effect on the magnitude of the average change in flux due to diurnal variation in SST i.e. diurnal covariations with SST have an almost negligible effect on flux.

This is also shown graphically in Fig. 2 where theoretical (yet realistic) diurnally varying physical forcings are used to drive the equations to compute the flux for the three different SST scenarios. Figure 2a shows three different SST scenarios: shown in black is diurnally-varying SST; shown in blue (dashed line) is the foundation temperature and in red is the mean of the diurnally varying SST over the time period (i.e. covariability is removed). Wind speed is chosen to be at $1 \mathrm{~m} \mathrm{~s}^{-1}$ to give the large diurnal warming in SST (above $3 \mathrm{~m} \mathrm{~s}^{-1}$ diurnal warming is unlikely, Gentemann et al., 2003). The other drivers needed are $T_{\text {air }}$ and SSI (Fig. 2b-c) which are set to be slightly out of phase with
SST (they peak $2.5 \mathrm{~h}$ before SST peaks to incorporate the time delay for the ocean warming. $T_{\text {dew }}$ is not shown but is taken to be $4^{\circ} \mathrm{C}$ less than $T_{\text {air }}$. The effect of SST and wind speed on heat fluxes are shown in Fig. 2d-e. The effect of SST on solubility is shown in Fig. 2f. The concentration of $\mathrm{CO}_{2}$ at the ocean skin $\left(\alpha_{s} p \mathrm{CO}_{2 a}\right)$ is shown in Fig. $2 \mathrm{~g}$. Since $\alpha_{w}$ and $p \mathrm{CO}_{2 w}$ (set to be $356 \mu \mathrm{atm}$ ) do not vary diurnally, the difference in the air and sea concentrations (Fig. $2 \mathrm{~h}$ ) is governed by $\left[\mathrm{CO}_{2 s}\right]$. The gas transfer velocity is affected by all of the drivers and shows some diurnal variation (increases at night) even when the SST is constant (Fig. 2i). Since the flux is the product of $\Delta\left[\mathrm{CO}_{2}\right]$ and $k$ using the mean SST (red line) leads to an overestimate of flux at night and an underestimate during the day but these are approximately balanced so that the mean flux is $0.10 \mathrm{~mol} \mathrm{~m}^{-2} \mathrm{a}^{-1}$ (black line). Using the mean $\triangle$ SST gives a mean flux of $0.11 \mathrm{~mol} \mathrm{~m}^{-2} \mathrm{a}^{-1}$ (red line) and using the foundation temperature gives a flux of $0.04 \mathrm{~mol} \mathrm{~m}^{-2} \mathrm{a}^{-1}$ (blue dashed line). Thus, using the foundation temperature significantly underestimates $\Delta\left[\mathrm{CO}_{2}\right]$ and so has a big effect on flux but errors caused by using the average diurnal warming are approximately balanced out (for steady wind conditions). The flux balances because it is dominated by the change in solubility with temperature (Eq. 32) which is approximately linear over the range of diurnal temperature variation (Fig. 2f). Using the approximation for the change in flux (Eq. 32) gives a mean flux 


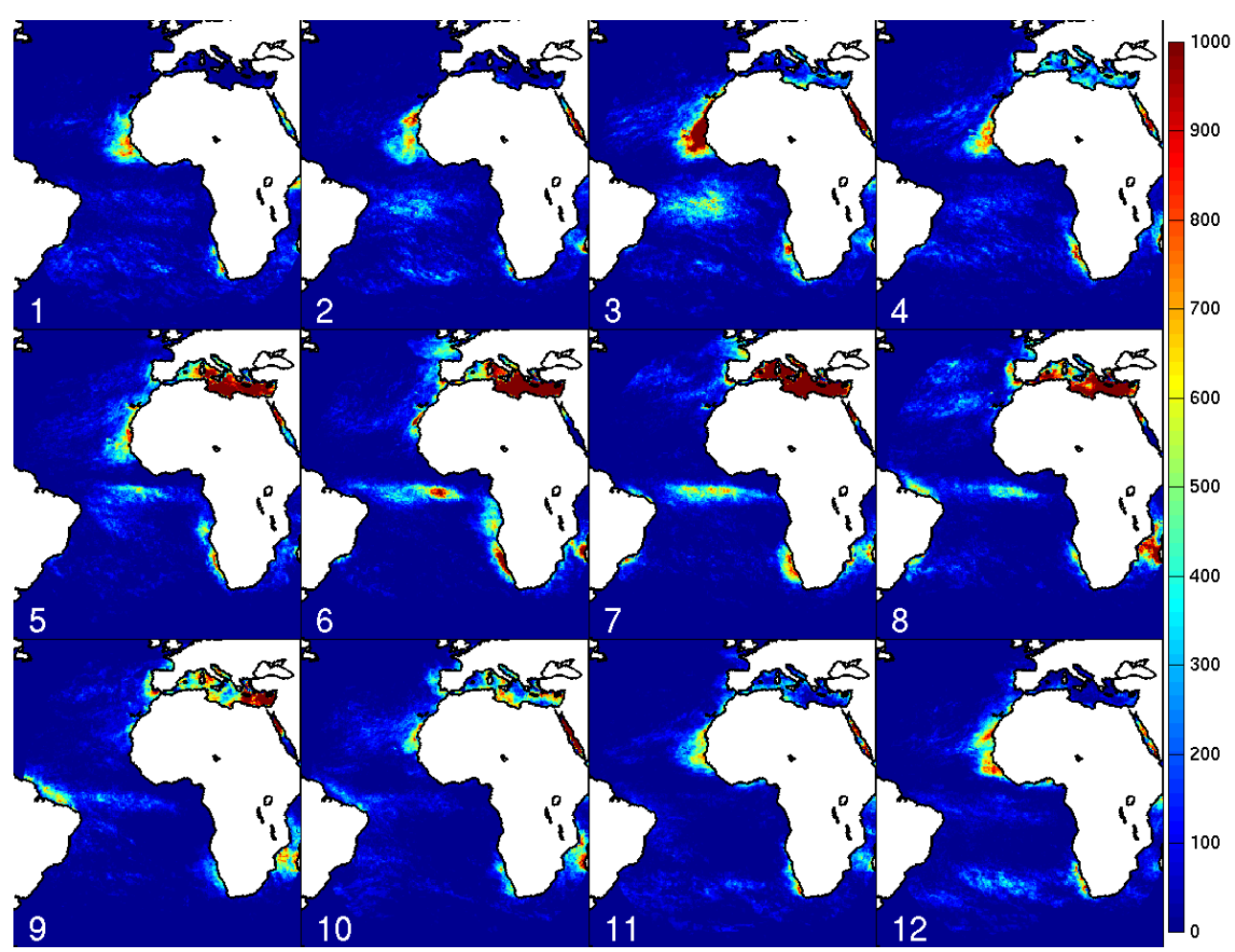

Fig. 7. Number of data points available to compute fluxes. Colorscale is saturated at 1000 to show data distribution by in data rich areas numbers go up to around 2600 .

of $0.096 \mathrm{~mol} \mathrm{~m}^{-2} \mathrm{a}^{-1}$ and using the average approximation (Eq. 34) gives $0.10 \mathrm{~mol} \mathrm{~m}^{-2} \mathrm{a}^{-1}$ (green and magenta lines respectively in Fig. 2j).

However, $\mathrm{CO}_{2}$ flux is not just affected by temperature but also by biological activity. Photosynthesis by phytoplankton removes dissolved inorganic carbon (DIC) from the surface waters, lowering $p \mathrm{CO}_{2 w}$ when there is sufficent light and nutrient available. Since light availability also varies diurnally the biological affect, which acts to increase $\mathrm{CO}_{2}$ ingassing, may eliminate the diurnal increases in outgassing caused by diurnal warming. We estimate the approximate magnitude of the biological effect as follows: Morel and Antoine (2002) show the average net primary production (NPP) over June 2001 or December 2000 to have a global maximum of $2 \mathrm{gC} \mathrm{m}^{-2} \mathrm{~d}^{-1}$ (which incidentally is higher than estimates given by Behrenfeld et al. (2005), and Behrenfeld and Falkowski, 1997). We convert this to the NPP over daylight hours by doubling it (assuming no photosynthesis over night, and assuming this is half of the day), and we assume photosynthesis occurs over a depth of $100 \mathrm{~m}$, so that the uptake of carbon from the water in one day is $40 \mathrm{mg} \mathrm{C} \mathrm{m}^{-3}$. This is equivalent to a decrease in DIC of $3.3 \mu \mathrm{mol} \mathrm{Cl}^{-1}$. Using equations representing the sea-water acid-base system with expressions for the dissociation constants of carbonic acid, hydrogen carbonate, boric acid and water from DOE (1994) we can compute the change in $p \mathrm{CO}_{2 w}$ for a given change in DIC. If DIC decreases by $3.3 \mu \mathrm{molCl}^{-1}$, and assuming a standard DIC concentration of $2058 \mu \mathrm{moll}^{-1}$, alkalinity of $2396 \mu \mathrm{moll}^{-1}$ (e.g. Palmer and Totterdell, 2001) and SST $=25^{\circ} \mathrm{C}$, the decrease in $p \mathrm{CO}_{2 w}$ is $5.7 \mu \mathrm{atm}$. This would result in a change in flux $\left(\Delta F_{\mathrm{bio}}\right)$ of $5.7 \times 10^{-6} k \alpha_{w}$, which at $25^{\circ} \mathrm{C}$ is $\sim 1.65 \times 10^{-4} k$. Equating this with Eq. (32) (and assuming $p \mathrm{CO}_{2 a} \approx 350 \mu \mathrm{atm}$ ), indicates that a change in solubility of $0.47 \mathrm{~mol} \mathrm{~atm}^{-1} \mathrm{~m}^{-3}$ is required to offset the biological influence. The change in solubility with temperature ranges from -0.92 to -0.6 for SSTs of $20-30^{\circ} \mathrm{C}$. Thus the increase in ingassing flux due to biological activity is equivalent to the increase in outgassing flux caused by an increase in SST of $\sim 0.5-0.7 \mathrm{~K}$. Therefore if surface nutrient is available it is possible that biological activity could eliminate the temperature-induced increase in outgassing for $\Delta \mathrm{SST} \leq \sim 0.7 \mathrm{~K}$. However, since diurnal warming generally occurs when the ocean is strongly stratified, these are the times when there is less surface nutrient available and biological activity is probably much lower than we have estimated.

The analysis presented herein required the Taka02 $p \mathrm{CO}_{2 w}$ climatology to be interpolated over the shelf sea regions. This is not ideal but, in the absence of a shelf sea $p \mathrm{CO}_{2 w}$ climatology, was the only approach. Figure 8 shows examples of the interpolation results for January and July. The method 

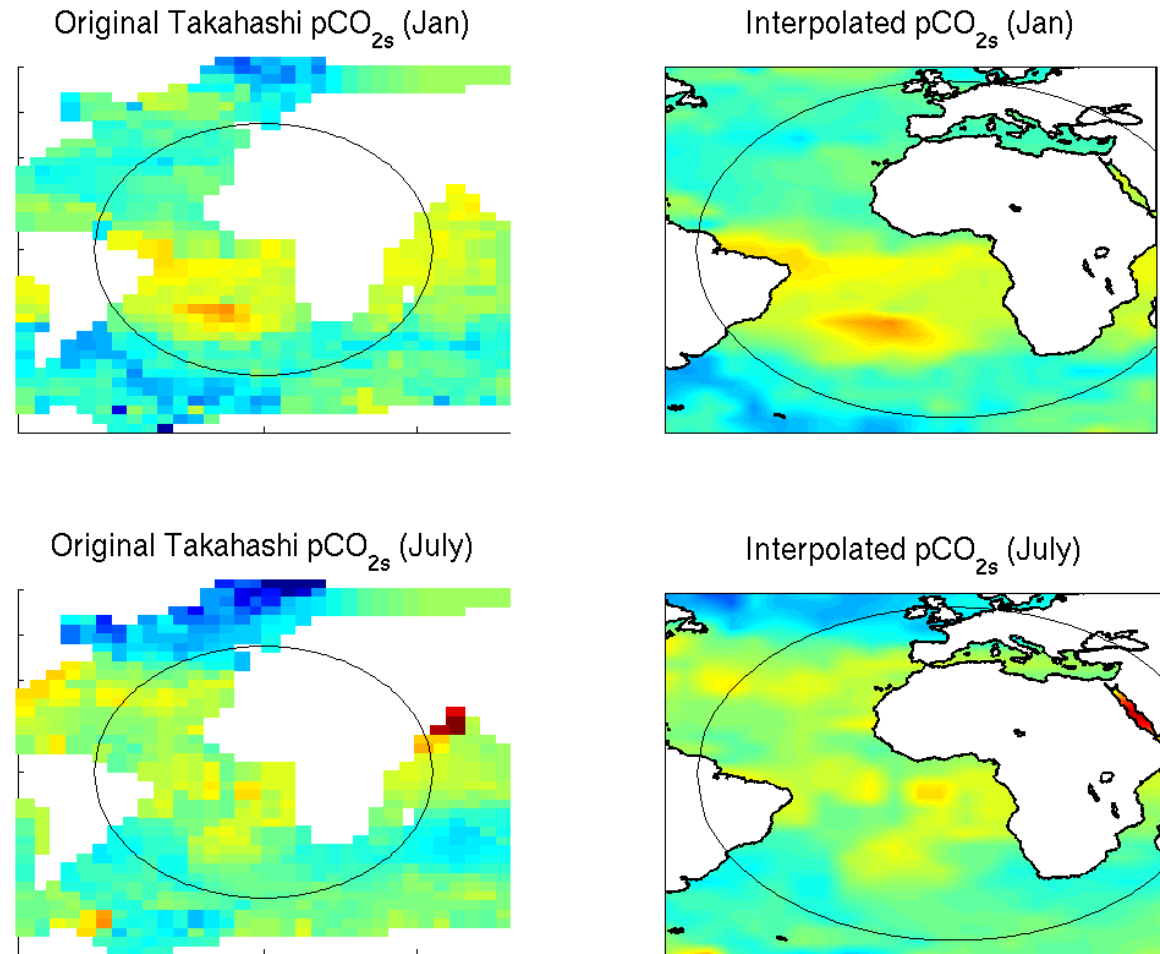

Interpolated $\mathrm{pCO}_{2 s}$ (July)
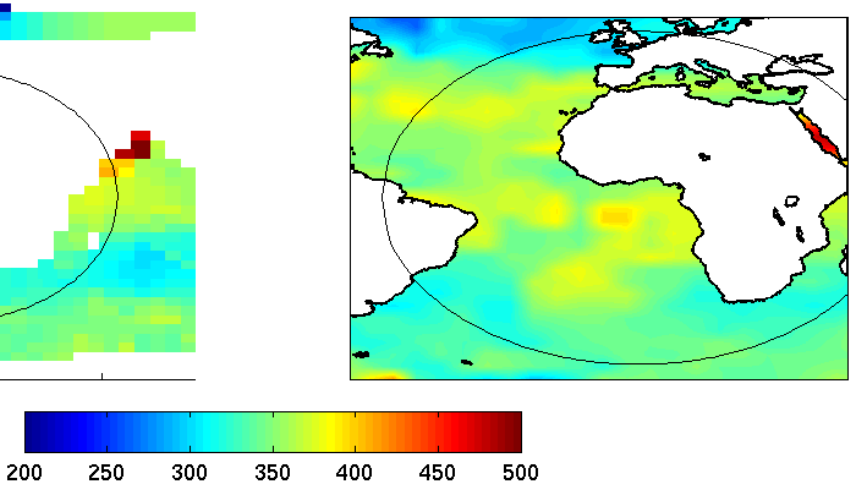

Fig. 8. Interpolating $p \mathrm{CO}_{2 w}$ from Taka02 for the reference year 1995 over the shelf seas for January (top row) and July (bottom row). Black circle indicates circumference of SEVIRI disk.

appears sensible through the Meditteranean Sea and around the coasts but very high values are estimated in the Red Sea (NE Africa) in July due to the high values in the Arabian sea in the Taka02 climatology. Whether or not the fluxes predicted over these regions are reasonable is unknown, however, since our concern is the difference in flux caused by SST variability, this is not critical. Similarly the Taka02 climatology is referenced to the year 1995, therefore the fluxes shown in this study are computed using driving data from 2005-2006 but can not be thought to be the actual fluxes for this period as the $p \mathrm{CO}_{2}$ fields have undoubtably changed since 1995.

There is also the issue of missing data. Since satellites measurements of SST are not possible through cloud, there are many missing data points. In fact in some regions there may not be a single satellite measurement for a month (see Fig. 7). Therefore, although the extreme diurnal warming events will occur under clear-sky conditions there may be more moderate warming events that are missed due to cloud.

Finally, these results must be put in context with the Atlantic carbon budget as a whole. It is likely that the regions not included in this analysis, e.g., higher latitudes, do not show strong diurnal warming (due to cooler temperatures and higher wind speeds), so it is possible that a reasonable pro- portion of the diurnal warming that occurs in the Atlantic is covered by this study (refer to Fig. 1). In the higher latitudes the Atlantic ocean becomes a very strong carbon sink so that the overall net flux for the Atlantic is $\sim-920 \mathrm{Tg} \mathrm{C} \mathrm{a}^{-1}$ (Takahashi et al., 2002). We find that the inclusion of diurnal warming increases outgassing in the region studied by $\sim 20 \mathrm{Tg} \mathrm{Ca}^{-1}$, if this does actually represent the effect of diurnal warming over the whole of the Atlantic then we can conclude that diurnal warming has a very small effect on the Atlantic carbon budget. However, when evaluating regional carbon budgets e.g. for the Mediterranean Sea, the impact of diurnal warming may be very important.

\section{Conclusions}

Diurnal variations in SST have a significant impact on $\mathrm{CO}_{2}$ flux over the SEVIRI disk region (central Atlantic ocean and Mediterranean). Including diurnal variability in SST increases the mass net flux out of the ocean from $9.6 \mathrm{Tg} \mathrm{Ca}^{-1}$ to $30.4 \mathrm{Tg} \mathrm{Ca}^{-1}$. At a local scale, average monthly fluxes may be increased by up to $\sim 0.2 \mathrm{molCO}_{2} \mathrm{~m}^{-2} \mathrm{a}^{-1}$. This is due to the decrease in solubility associated with $\triangle \mathrm{SST}$ rather than covariations between diurnally varying variables (which causes a decrease in outgassing of $\sim 1 \mathrm{Tg} \mathrm{Ca}^{-1}$ ). 
Therefore, it is important that the additional outgassing of $\mathrm{CO}_{2}$ due to $\Delta \mathrm{SST}$ is accounted for in regional net flux evaluations, but it is not necessary to include the diurnal time structure in SST.

Edited by: W. E. Asher

\section{References}

Asher, W. and Wanninkhof, R.: Transient tracers and air-sea gas transfer, J. Geophys. Res., 103, 15939-15958, 1998.

Behrenfeld, M. J. and Falkowski, P. G.: Photosynthetic rates derived from satellite-based chlorophyll concentration, Limnol. Oceanogr., 42(1), 1-20, 1997.

Behrenfeld, M. J., Boss, E., Siegel, D. A., and Shea, D. M.: Carbon-based ocean productivity and phytoplankton physiology from space, Global Biogeochem. Cy., 19, GB1006, doi:10.1029/2004Gb002299, 2005.

Doney, S.: Irreversible thermodynamics and air-sea exchange, J. Geophys. Res., 100, 8541-8553, 1995.

Donlon, C., Robinson, I, Casey, K., Vasquez, J., Armstrong, E., Gentemann,C., May, D., LeBorgne, P., Piolle, J., Barton, I., Beggs, H., Poulter, D. J. S., Merchant, C. J., Bingham, A., Heinz, S., Harris, A., Wick, G., Emery, B., Stuart-Menteth, A., Minnett, P., Evans, B., Llewellyn-Jones, D., Mutlow, C., Reynolds, R., Kawamura, H., and Rayner, N.: The Global Ocean Data Assimilation Experiment (GODAE) High Resolution Sea Surface Temperature Pilot Project (GHRSST-PP), B. Am. Meteorol. Soc, 88(8), 1197-1213, 2007.

Fairall, C. W., Bradley, E. F, Godfrey, J. S., Wick, G. A., Edson, J. B., and Young, G. S.: Cool-skin and warm-layer effects on sea surface temperature, J. Geophys. Res., 101(C1), 1295-1308, 1996a.

Fairall, C. W., Bradley, E. F., Rogers, D., Edson, J. B., and Young, G. S.: Bulk parameterization of air-sea fluxes for Tropical Ocean-Global Atmosphere Coupled-Ocean Atmosphere Response Experiment, J. Geophys. Res., 101(C2), 3747-3764, 1996b.

Fairall, C. W., Hare J. E., Edson, J. B., and McGillis, W.: Parameterization and micrometeorological measurement of air-sea gas transfer, Bound.-Lay. Meteorol., 96, 63-105, 2000.

Gentemann, C. L., Donlon, C. J., Stuart-Menteth, A., and Wentz, F.: Diurnal signals in satellite sea surface temperature measurements, Geosphy. Res. Lett., 30(3), 1140, doi:10.1029/2002GL016291, 2003.

GLOBALVIEW- $\mathrm{CO}_{2}$ : Cooperative Atmospheric Data Integration Project - Carbon Dioxide, CD-ROM, NOAA CMDL, Boulder, CO, online available at: fttp://ftp.cmdl.noaa.gov/ccg/co2/ GLOBALVIEW, 2000.

Godfrey, J. S. and Beljaars, A. C. M.: On the turbulent fluxes of buoyancy, heat and moisture at the air-sea interface at low wind speeds, J. Geophys. Res., 96(C12), 22043-22048, 1991.

Hare, J. E., Fairall, C. W., McGillis, W. R., Edson, J. B., Ward, B., and Wanninkhof, R.: Evaluation of the National Oceanic and Atmospheric Administration/Coupled-Ocean Atmosphric Response Experiment (NOAA/COARE) air-sea gas transfer parameterization using GasEx data, J. Geophys. Res., 109, C08S11, doi:10.1029/2003JC001831, 2004.
Jahne, B., Heinz, G., and Dietrich, W.: Measurement of the diffusion coefficients of sparingly soluble gases in water with a modified Barrer method, J. Geophys. Res., 92, 10767-10776, 1987.

Jeffery, C. D., Woolf, D. K., Robinson, I. S., and Donlon, C. J.: One-dimensional modelling of the convective $\mathrm{CO}_{2}$ exchange in the Tropical Atlantic, Ocean Model., 19, 161-182, 2007.

Kettle, H. and Merchant, C. J.: Systematic errors in global air-sea $\mathrm{CO}_{2}$ flux caused by temporal averaging of sea-level pressure, Atmos. Chem. Phys., 5, 1459-1466, 2005, http://www.atmos-chem-phys.net/5/1459/2005/.

LeBorgne, P., Legendre, G., and Marsouin, A.: Operational SST retrieval from MSG/SEVIRI data, paper presented at the 2006 EUMETSAT Conference, Helesinki, Finland, 12-16 June, 2006.

Liss, P. S. and Merlivat, L.: Air-sea gas exchange rates: Introduction and synthesis, in: The Role of Air-Sea Exchange in Geochemical Cyclig, edited by: Buat-Menard, P., Dreidel, Norwell, Mass., 113-127, 1986.

Liss, P. S. and Slater, P. G. : Fluxes of gases across the air-sea interface, Nature, 247, 181-184, 1974.

McGillis, W. R. and Wanninkhof, R.: Aqueous $\mathrm{CO}_{2}$ gradients for air-seea flux estimates, Mar. Chem., 98, 100-108, 2006.

McGillis, W. R., Edson, J. B., Zappa, C. J., Ware, J. D., McKenna, S. P., Terray, E. A., Hare, J. E., Fairall, C. W., Drennan, W., Donelan, M., DeGrandpre, M. D. Wanninkhof, R., and Feely, R. A.: Air-sea $\mathrm{CO}_{2}$ exchange in the equatorial Pacific, J. Geos. Res., 109, C08S02, doi:10.1029/2003JC002256, 2004.

McNeil, C. L. and Merlivat, L.: The warm oceanic surface layer: Implications for $\mathrm{CO}_{2}$ fluxes and surface gas measurements, Geophys. Res. Lett., 23(24), 3575-3578, 1996.

Merchant, C. J., Filipiak, M. J., Le Borgne, P., Roquet, H., Autret, E., Piolle, J.-H., and Lavender, S.: Diurnal warm-layer events in the western Mediterranean and European shelf seas, Geophys. Res. Lett., 35, L04601, doi:10.1029/2007GL033071, 2008.

Miller, M. J., Beljaars, A. C. M., and Palmer, T. N.: The sensitivity of the ECMWF model to the parameterization of the evaporation from the tropical oceans, J. Climate, 5(5), 418-434, 1991.

Monahan, E. C. and Spillane, M. C.: The role of whitecaps in airsea gas exchange, In: Gas Transfer at Water Surfaces, edited by: Brutsaert, W., and Jirka, G. H., Dreidel, Norwell, Mass., 495504, 1984.

Morel, A. and Antoine, D.: Small critters - big effects, Science, 296, 1980-1982, 2002.

Nightingale, P. D., Malin, G., Law, C. S., Watson, A. J., Liss, P. S., Liddicoat, M. I., Boutin, J., and Upstill-Goddard, R. C.: In situ evaluation of air-sea gas exchange parameterizations using novel conservative and volatile tracers, Global Biogeochem. Cy., 14, 373-387, 2000.

Olsen, A., Omar, A. M., Stuart-Menteth, A. C., and Triñanes, J. A.: Diurnal variations of surface ocean $p \mathrm{CO}_{2}$ and sea-air $\mathrm{CO}_{2}$ flux evaluated using remotely sensed data, Geophys. Res. Lett., 31, L20304, doi:10.1029/2004GL020583, 2004.

Palmer, J. R. and Totterdell, I. J.: Production and export in a global ocean ecosystem model, Deep-Sea Res., 48(5), 11691198, 2001.

Robertson, J. E. and Watson, A. J.: Thermal skini effect of the surface ocean and its implications for $\mathrm{CO}_{2}$ uptake, Nature, 358, 738-740, 1992.

Saunders, P. M.: The temperature of the ocean-air interface, J. Atmos. Sci., 24, 269-273, 1967. 
Schumann, U.: Minimum friction velocity and heat transfer in the rough surface layer of a convective boundary layer, Bound. Lay. Meteorol., 44, 311-326, 1988.

Soloviev, A. V. and Schlüssel, P.: Parameterization of the cool skin of the ocean and of the air-ocean gas transfer on the basis of modeling surface renewal theory, J. Phys. Oceanogr., 24, 13391346, 1994.

Stramma, L., Cornillon P., Weller, R. A., Price J. F., and Briscoe, M. G.: Large diurnal sea-surface temperature variability: Satellite and insitu measurements, J. Phys. Oceanogr., 16, 827-837, 1986.

Stuart-Menteth, A. C., Robinson, I. S., and Challenor, P. G.: A global study of diurnal warming using satellite-derived sea surface temperature, J. Geophys. Res., 108(C5), 3155, doi:10.1029/2002JC001534, 2003.

Stull, R. B.: A convective transport theory for surface fluxes, J. Atmos. Sci., 51(1), 3-22, 1994.

Takahashi, T., Sutherland, S. C., Sweeney, C., Poisson, A., Metzl, N., Tillbrook, B., Bates, N., Wanninkhof, R., Feely, R. A., Sabine, C., Olafsson, J., and Nojiri, Y.: Global sea-air $\mathrm{CO}_{2}$ flux based on climatological surface ocean $p \mathrm{CO}_{2}$, and seasonal biological and temperature effects, Deep Sea Res. Part II, 49, 16011622, 2002.

Takahashi, T., Olafsson, J., Goddard, J., Chipman, D. W., and Sutherland, S. C.: Seasonal variation of $\mathrm{CO}_{2}$ and nutrients in the high-latitude surface oceans: a comparative study, Global Biogeochem. Cy., 7, 843-878, 1993.
Van Scoy, K. A., Morris, K. P. Robertson, J. E., and Watson, A. J.: Thermal skin effect and the air-sea flux of carbon dioxide: A seasonal high-resolution estimate, Global Biogeochemical Cy., 9(2), 253-262, 1995.

Wanninkhof, R.: Relationship between wind speed and gas exchange over the ocean, J. Geophys. Res., 97(C5), 7373-7382, 1992.

Wanninkhof, R. and McGillis, W. R.: A cubic relationship between air-sea $\mathrm{CO}_{2}$ exchange and wind speed, Geophys. Res. Lett., 26(13), 1889-1829, 1999.

Weiss, R. F.: Carbon dioxide in water and seawater: the solubility of a non-ideal gas, Mar. Chem., 2, 203-215, 1974.

Weiss, R. F. and Price, B. A.: Nitrous-oxide solubility in water and seawater, Mar. Chem., 8, 347-359, 1980.

Woolf, D. K.: Bubbles and their role in gas exchange, in: The Sea Surface and Global Change, edited by: Duce, R. A. and Liss, P. S., Cambridge University Press, New York, USA, 173-205, 1997.

Wentz, F. J.: A well calibrated ocean algorithm for special sensor microwave/imager, J. Geophys. Res., 102(C4), 8703-8718, 1997. 